\title{
EL TEATRO DE LOPE A LA VERA DEL SIGLO XXI: LA ADAPTACIÓN CINEMATOGRÁFICA DE EL PERRO DEL HORTELANO
}

\author{
Bruno Andrés Longoni ${ }^{l}$ \\ Universidad Industrial de Santander
}

\begin{abstract}
Resumen: Nuestro trabajo propone analizar en detalle la adaptación cinematográfica que la directora española Pilar Miró realizó de $E l$ perro del hortelano (1612), una de las más reconocidas comedias palatinas del más prolífico autor teatral del siglo de oro, Félix Lope de Vega y Carpio. En cada uno de sus registros fílmicos (guion, montaje, vestuario, actuaciones, escenificación, enfoque de cámara, simbología) señalaremos una lectura personal del texto canónico que conlleva implícito un debate esencial en la crítica literaria moderna: el solo hecho de mediar casi cuatrocientos años entre la pieza teatral y la película nos debe recordar que toda adaptación acarrea una relectura en clave moderna que acaba creando, inexorablemente, un sentido nuevo surgido de los valores estéticos e ideológicos del presente.
\end{abstract}

Palabras clave: Lope de Vega ; El perro del hortelano; Cine; Adaptación.

Recibido: 5 de marzo de 2019

Aprobado: 30 de marzo de 2019

\section{LOPE'S THEATRE ON THE EDGE OF THE 21ST CENTURY: THE CINEMATOGRAPHIC ADAPTATION OF THE GARDENER'S DOG}

\begin{abstract}
Our work seeks to analyze in detail El perro del hortelano's cinematographic adaptation made by spanish director Pilar Miró. The original play is one of most renowned palatine comedies of the prolific Golden Age's author, Félix Lope de Vega y Carpio. In each of its features (script, edition, costumes, performances, staging, camera approach, symbology), we will point out a personal reading of the canonical text that implicitly involves an essential debate in modern literary criticism: four hundred years between the play and the film should remember us that every adaptation leads to a rereading in a modern key that ends up creating, inexorably, a new sense arising from the aesthetic and ideological values of the present.
\end{abstract}

\footnotetext{
${ }^{1}$ Docente en la universidad Industrial de Santander. Licenciado en letras cum lade (orienta-ción en lingüística formal) por la Universidad de Buenos Aires (2007) y máster en literatura española e hispanoamericana cum lade por la Universidad de Barcelona (2016). Correo electrónico: brunoandreslongoni@yahoo.com.ar
} 


\section{BRUNO ANDRÉS LONGONI}

Keywords: Lope de Vega ; El perro del hortelano; Film; Adaptation.

\section{Por qué Lope}

Como ya se entrevé a partir de las versiones modernas de dos de sus clásicos (El perro del hortelano de 1996, comedia palatina dirigida por Pilar Miró y La dama boba de 2006, comedia de capa y espada dirigida por Manuel Iborra), los directores de cine encuentran sólidos motivos para adaptar cinematográficamente una comedia de Lope de Vega. Al fin y al cabo, el teatro áureo anticipa en más de tres siglos la estructura narrativa que adoptaría el guion cinematográfico en el cine de masas: la disposición tripartita, donde los tres actos escénicos se regeneran como principio-nudo-desenlace (estructura impartida casi como dogma en cualquier curso de cine), la linealidad narrativa, la tensión volcada sobre la intriga de la trama más que sobre los personajes no pocas veces tópicos y la resolución que recompone el orden alterado por conflictos de honra (Peribáñez y el comendador de Ocaña, El mejor alcalde, el rey), de revuelta social (Fuenteovejuna), de enredos amorosos ( $L a$ viuda valenciana, La dama boba) o de historicismo providencialista (El nuevo mundo descubierto por Cristóbal Colón). Ello no significa, vale aclarar, que un director de cine no deba enfrentar ciertas complicaciones al adaptar una obra de Lope. Para empezar, como revela Pérez-Sierra (1995), el teatro del siglo de oro, por lo demás verbalmente esplendoroso en su polimetría, suele carecer casi por completo de didascalias y de indicaciones escénicas: la ambientación, el vestuario, la iluminación y el comportamiento gestual de los personajes queda implícito en los diálogos, y corresponde al director inferirlos.

\section{Vestuario y actuaciones}

Uno de los mayores aciertos en la adaptación de Pilar Miró consiste en el variopinto empleo de los colores del vestuario como encarnación metafórica de las alteraciones sentimentales de los personajes. Puesto que la mayoría de los personajes resultan arquetípicos, su vestuario se mantendrá también invariable: allí tenemos al gracioso o figura del donaire, Tristán, cuyas prendas mugrientas, su rostro sucio y sus hábitos alimenticios (come con las manos y habla con la boca llena) acaban 
de configurarlo como un personaje típicamente picaresco a tal punto que Miró ha cercenado todas sus intervenciones cultas -en la obra de Lope, Tristán traza correspondencias mitológicas como la de Héctor en Troya, o compara a Teodoro con César Borgia, lo cual ha suscitado un interesante estudio de Antonucci (2004) sobre el carácter maquiavélico y manipulador del protagonista de la obra. El único cambio de vestuario que observamos en Tristán resulta de un humor grotesco: ataviado como un morisco (Lope apunta en su obra que el personaje debe verse como un griego), su gesticulación obscena acompaña su delirante estratagema sobre el destino del hijo de Ludovico.

Marcela, cuyapasión porTeodoroasícomo su interesado acercamiento a Fabio se constituyen en sus rasgos sobresalientes, tampoco altera su vestuario ni su comportamiento gestual: las expresiones de la actriz, Ana Duato, que, con sus ojos desmesuradamente abiertos y con el tono agudo que expresa su carácter algo ingenuo e infantil, la configuran, como a Tristán, en tanto personaje caricaturesco, van en la línea de las decisiones directrices de Miró: los dos sonetos que Lope pone en boca de este personaje se sacrifican en la película, lo cual redunda en un personaje aún más tópico y unidimensional.

Teodoro, el criado protagonista que, supeditado a la voluntad de su señora, resulta previsible en su comportamiento emocional, se mostrará vistiendo, en consecuencia, el mismo traje azul a lo largo de toda la película (sugiriendo, acaso, su frialdad dentro del maquiavélico interés que su afecto por Diana encierra al tratarse de un casamiento que, de llevarse a cabo, traería aparejado un notable ascenso social). La única alteración en su vestuario tendrá lugar sobre el final de la cinta, cuando lo vemos ataviado de un traje formal color verde (¿esperanza?) con su pecho atravesado por cadenas de oro que dan cuenta de su nueva clase social tras haber sido reconocido como hijo del conde Ludovico. Su lenguaje corporal resulta sencillo, por tratarse Teodoro de un personaje cuyas palabras no se han disociado aun de sus acciones: cuando, entusiasmado por Diana, acaba su relación sentimental con Marcela ("Marcela, queda con Dios. / Aquí acaba de los dos / el amor, no la amistad", II, vv.1477-1479), Carmelo Gómez, el actor protagonista en la película de Miró, se quita de encima a su adoradora con cautela 
evitando mirarla a los ojos, como si su solo contacto pusiese en peligro sus posibilidades con Diana.

Desde la Diana (1559) de Montemayor, este nombre se ha vuelto en la literatura arquetipo pastoril de la ninfa desdeñosa y volátil. Sus vaivenes emocionales la llevarán, por lo tanto, a vestir toda la gama de colores vinculados, en su gran mayoría, al rojo. Tras despertar súbitamente en el medio de la noche por los ruidos de la huida furtiva de Teodoro y Tristán, Diana se nos presenta en un camisón de seda rosada, color suave y apaciguado, símbolo de lo femenino. La interrogación retórica en el octosílabo de Fabio (“¿Hay tal traición? ¿Tal maldad?”, I, v.24) se traslada en la película a boca de Diana, con el objetivo de caracterizarla como una mujer rigurosa y de poca paciencia. Al día siguiente, cuando sus celos por Marcela comiencen a despertar su amor por Teodoro, Diana lucirá un ostentoso vestido ambarino para recitar, con voz en off y miradas de reojo hacia Teodoro, el primer soneto de la obra dando a entender, por vez primera, su pasión por él. De allí la veremos, a continuación, coquetear abiertamente con su criado: le recita un soneto compuesto por una presunta amiga que se ha enamorado por celos y exige a Teodoro que escriba otro soneto como refutación del suyo. Puesto que nos encontramos a mitad de camino de su enamoramiento, el vestido que luce ahora es anaranjado. En la comedia de Lope, el punto álgido de su pasión corresponde al final del primer acto, diseñado por Pilar Miró como una suerte de locus amoenus donde los amantes navegan sosegadamente por los canales napolitanos sobre una góndola conducida por Teodoro. Intrigada por su engañoso y lisonjero criado, esta escena central nos muestra a la protagonista ataviada en un traje color rojo intenso que expresa su pasión contenida que solo consigue desatar tras fingir una caída con el único objeto de pedir, no sin obvias connotaciones, la mano de Teodoro. El lenguaje corporal de Emma Suárez, la actriz protagónica, con sus ojos acuosos, la cara inyectada en sangre y el pulso acelerado, nos habla del clímax romántico de la pareja. Su emocionalidad pendular obliga a representarla, acto continuo, participando de una misa ataviada de azul, color frío, cubierta por un velo blanco como símbolo de su virginidad tan frecuentemente asociada a las ninfas pastoriles $y$, en consecuencia, de su inaccesibilidad 
para sus dos nuevos pretendientes, Ricardo y Federico, a quienes dedica pocas y protocolares palabras. A partir de allí regresa a la gama de los colores cálidos: rojo cuando se encuentra cerca de Teodoro y morado, como si se tratara de sangre coagulada, cuando su relación comienza a empantanarse. Para representar las dudas de su protagonista, su imposibilidad de expresar sus deseos por su criado y la presión que debe soportar como condesa de Belflor, Miró nos la presenta yendo y viniendo en movimiento circular, con toda su cohorte a corta distancia, como si se tratara de un animal enjaulado. A punto de quebrarse, Diana se expresa en la metáfora de la cuerda que contienen los dos últimos endecasílabos de uno de los más bellos sonetos de la obra: "mas si tanto el honor tira la cuerda, / por Dios, que temo que se rompa el arco" (II, vv. 2132-2133). Esta escena la encuentra sentada, vestida de color violeta (la descomposición del rojo), cuando se quita un zapato y se masajea el pie, como símbolo de la necesidad de liberación y descarga que la apremian. El último vestido que le conoceremos, cuando se disponga a casarse con Teodoro, será el anaranjado, rememorando con ello el origen del idilio, cuando los amantes intercambiaban sendos sonetos.

\section{Montaje, enfoque, símbolos}

Mientras Lope, quizás para recargar las tintas sobre la intriga, abre la narración in media res con la huida sibilina de Tristán y Teodoro, Miró pasa de un plano panorámico del palacio de Belflor con sus dos torres rematadas en capiteles al beso apasionado de Teodoro y Marcela. Como en Un perro andaluz (1929), el corto surrealista donde Buñuel y Dalí emplean la luna cortada por la nube como metáfora del ojo cortado por la navaja, las dos torres iluminadas por la dudosa luz del día que impone la alborada sirven de metáfora para los dos amantes subrepticios que, ocultos en la noche, son descubiertos por el rosicler de la aurora.

Tres montajes son recurrentes a lo largo de la película. El primero de ellos sigue a la primera escena de celos protagonizada por Diana: la aristocracia juega a los bolos a la intemperie donde suenan la cítara, la flauta y otros instrumentos de época, Octavio golpea en reprimenda al criado enano. La yuxtaposición de escenas sugiere tenuemente que los enredos amorosos son parte integral del universo preponderantemente 
lúdico del palacio, donde el tedio obliga a perpetuas distracciones (amor, bolos, música, violencia clasista). Quizá para enfatizar el mundo hiperculturizado e hipercodificado del barroco, un grupo de niños ataviados suele aparecer con elegante vestuario de época practicando, también al aire libre, una danza de pasos rígidos. Por último, el clásico número musical que Lope de Vega suele incluir en cada una de sus comedias aparece resuelto, en la cinta, con música de fondo, la fuente en perpetua ebullición y un dubitativo Teodoro empujado por Tristán. Este montaje también propone un interesante juego de asociaciones: niños obligados a una diversión rigurosamente reglada (el amor como un juego plagado de restricciones, como aquella que prohíbe el amor interclasista), la fuente en ebullición y Teodoro en movimiento (aquello que rebalsa, que se desborda de su estructura, como Teodoro en sus anhelos de ascenso social).

Uno de los enfoques de cámara más interesantes lo hallamos al final del primer acto cuando Teodoro, ya solitario en la góndola después de haber oído la confesión amorosa por parte de Diana, observa directamente hacia la lente y declama un soneto. La cámara se ubica sobre la embarcación misma, acompañando el movimiento sinuoso del agua que mece al protagonista, como si el espectador fuera forzado a adoptar su punto de vista, los leves devaneos de su inquietud amorosa en franco contraste con el paisaje primaveral y la música etérea que completan la escena. Por último, habría que mencionar la escena de la bofetada: el plano de costado nos muestra a los amantes en los extremos de la pantalla, con la salvedad de que los escalones dispuestos con la silla elevada le otorgan a Diana una superioridad de más de dos cabezas por sobre Teodoro. La sociedad de la época establece una rígida jerarquía entre los amantes, mas no así el enfoque de la cámara, que representa una visión moderna y democrática al presentarlos nivelados, más allá de los gritos in crescendo que ambos se dedican.

Ambientada en la cocina, la escena siguiente representará el "descenso a los infiernos" de Diana, ya dispuesta a enredarse sentimentalmente con su criado, a quien le pide, como seña de amor, el pañuelo ensangrentando. Antes de retirarse, toma una tostada que encuentra sobre la mesa y la muerde mientras observa, provocadora, a 
Teodoro. Si el perro del hortelano era aquel que, como reza el dicho, "ni come ni comer deja" (II, v. 2299), Diana, en cambio, ya ha tomado una decisión al llevar el bocado a la boca.

\section{Lenguaje e ideología}

Por otro lado, casi cuatro siglos de distancia entre la obra original y su moderna adaptación cinematográfica a cargo de Pilar Miró implican, desde luego, nuevos desafíos, tanto lingüísticos (¿respetar a rajatabla la polimetría de un autor canónico o aggiornare su castellano, suavizarlo a los oyentes contemporáneos a riesgo de incidir sobre el verso?) como ideológicos (¿podemos trasplantar sin más el anacrónico discurso de la aristocracia europea sobre los impedimentos de un matrimonio entre desiguales a la democrática y republicana España finimilenial?).

En lo que a decisiones lingüísticas respecta, la directora se ha decantado por cierta modernización del castellano de Lope con leves intervenciones sobre el texto original: o bien anteponer, por ejemplo, los pronombres al verbo conjugado en vez de fusionarlos con él como correspondía en la sintaxis barroca del castellano: "Díjete" (I, v. 344), “Hame” (I, v. 515), “Búrlaste?” (I, v. 772), “¿Rasgástele?” (II, v. 1368) y “¿Llamábasme?” (II, v. 2145) se reordenan, sin alterar ni la métrica ni la rima del verso, en “Te dije”, "Me ha”, “¿Te burlas?”, “Le rasgaste?” y “¿Me llamabas?”; o bien poner al día los arcaísmos léxicos sin efectos colaterales sobre el verso: "A tu hechura manda" (I, v. 513), "Entra y prueba" (I, v. 596), "anda salido estos días" (I, v. 605) o los innumerables empleos de "agora" (I, v. 722, 972, 1169; etc.), se reemplazan por "a tu gusto manda", "anda y prueba", "anda muy pobre estos días" y "ahora". Los únicos versos agregados al texto original de Lope por la dupla de guionistas (Pilar Miró y Rafael Pérez Sierra) han sido precisamente los últimos, respondiendo a la españolísima estructura del romance con rima asonante $(-e, a-)$ :

TRISTÁN Muy bien me pagas señor

Por salir en tu defensa

¿No eran bastantes dos bodas

Para un día? 
TEODORO ¿Tú te quejas?

DIANA Qué pronto os llevan el hijo

LUDOVICOEsta vez, será sin penas

DIANA Yo os lo guardo que sería

descuido si lo perdiera.

(El perro del hortelano)

Debe reconocerse, por lo demás, que la versión cinematográfica dirigida por Pilar Miró representa una adaptación respetuosa del texto original: al igual que en la versión moderna de La dama boba (2006) dirigida por Manuel Iborra, la polimetría de Lope sobrevive y los diálogos, salvo contados casos, se mantienen sin alteraciones. La eliminación de cerca del veinte por ciento del texto original de Lope responde, en ambas adaptaciones, a necesidades de dinamismo narrativo: los fragmentos que se han eliminado resultan, en su gran mayoría, meramente accesorios, o responden a un anhelo de concentrar la densidad psicológica en la dupla protagonista en detrimento del resto de los personajes (recordemos que Marcela ve sacrificado sus dos sonetos, así como Tristán sus intervenciones eruditas, pues ambos personajes aparecen caricaturizados).

$\mathrm{Al}$ girar El perro del hortelano en torno de temas predominantemente amorosos, se entiende que sean las redondillas las que superpueblen los diálogos; en su Arte nuevo de hacer comedias nos informa el autor que "son los tercetos para cosas graves, / y para las de amor, las redondillas" (Vega Carpio 17). De las más de mil doscientas obras atribuidas a Lope, nos encontramos aquí con la que contiene mayor cantidad de sonetos; nueve en total, de los cuales sobreviven tan solo cinco en la película. Su musicalidad inspirada sin igual lo vuelve la forma perfecta "en los que aguardan" (6), especialmente si se trata del suspiro de un amante tras haber quedado solo/a luego de una revelación trascendental. Siendo el "aparte" indicado por Lope, Miró establece que sus personajes reciten sus sonetos con voz en off, recurso que hábilmente respeta la indicación de Lope si entendemos que es el espectador (y no el resto de los personajes) quien consigue acceder con ello al mundo interior de quien declama. Por otro lado, el hecho de que Ricardo se exprese casi 
exclusivamente en octavas reales (es decir, a la estrofa vinculada a la épica belicista), nos da la pauta de que se trata de un personaje torpe en materia amorosa (y, por lo tanto, de que fracasará en su empresa de seducción sobre la condesa de Belflor). Mientras Ricardo y Federico orbiten alrededor de Diana en la misa, será Teodoro quien declamará, también con voz en off, pero ya no en soneto sino en décimas:

Id en buen hora, aunque os den

mil muertes por atrevido;

que no se llama perdido

el que se pierde tan bien.

Como a otros dan parabién

de lo que hallan, estoy tal,

que de perdición igual

os le doy; porque es perderse

tan bien, que puede tenerse

envidia del mismo mal.

(II, vv. 1318-1327)

Aquí Lope nos revela un aspecto esencial del protagonista: la décima no corresponde al soliloquio amoroso como lo hace, por ejemplo, el soneto, sino que es una forma adoptada para el razonamiento filosófico (no en vano veremos a Segismundo discurrir sobre la naturaleza de la vida a partir de esta estrofa especular en La vida es sueño). Como Faetón o Ícaro, sus mitos de referencia, Teodoro está dispuesto a arrojarse heroicamente hacia la hazaña, así esté condenado a caer con gloria. A diferencia de ellos, no obstante, Teodoro no tiene nada por perder y todo por ganar: sus décimas dejan traslucir el carácter especulativo e interesado de su amor por Diana, y representan la inversión exacta de aquel soneto inicial ("Mil veces he advertido en la belleza...", I, v. 325) proferido por la protagonista quien se halla, vale decir, en una posición diametralmente opuesta.

Aquí hallamos una diferencia considerable entre la versión de Lope y su adaptación cinematográfica: Teodoro, cuyo interés económico nubla gran parte de sus conductas, se nos presenta en la película como un joven 
desinteresado que responde a motivos estrictamente sentimentales, víctima de las perpetuas mudanzas de ánimo que distinguen a su ama. Es como si, ambientada a finales de milenio, la versión cinematográfica sencillamente le restará valor a la feroz incompatibilidad que, hacia 1600 , volvía escandalosa cualquier relación amorosa entre una condesa y su criado.

\section{El fin de la historia}

El perro del hortelano, comedia palatina luminosa como pocas, pareciera poner sutilmente en tela de juicio la lógica aristocrática y su discurso basado en la supremacía de la sangre, si bien en el artificio de su final (la estratagema de Tristán que opera como un verdadero deus ex machina al posibilitar el casamiento entre desiguales) reina y prevalece, como suele ser el caso en Lope de Vega, el orden social vigente. Hay un punto, no obstante, en el cual Lope jamás dejará de ser un autor de una modernidad palmaria: nos referimos a la caracterización de las relaciones humanas en términos estrictamente económicos, a las reflexiones que suelen acompañar los sentimientos de sus personajes, quienes jamás dejan de especular sobre la dote aportada por la novia o sobre el título nobiliario aportado por el novio.

Rodada a finales de milenio, la adaptación cinematográfica a cargo de Pilar Miró renueva esa reflexión sobre la naturaleza económica de las relaciones interclasistas y sobre la (ingenua) noción de igualdad que la ideología neoliberal, globalmente difundida durante los años noventa, ha preconizado bajo el paradigma del fin de la historia (equivalente a sostener, sin más, el fin de los conflictos interclasistas ante la imposición ubicua del mercado y la sociedad de consumo). No resulta casual, en ese sentido, que la película cierre con una nota frívola al plasmar una fiesta generalizada donde todos, ricos y pobres, dejan de lado sus diferencias en aras del amor (genuino o interesado). 


\section{Referencias}

Antonucci, Fausta. Teodoro y César Borgia: una clave para la interpretación de El perro del hortelano. Memoria de la palabra: Actas del VI Congreso de la Asociación internacional Siglo de Oro. Burgos-La Rioja. 2004.15-19. Impreso.

De Kurlat, Frida Weber. "El perro del hortelano, comedia palatina". Nueva Revista de Filología Hispánica, 24 (2), 1975: 339-363.Impreso.

Hartztfeld, Helmut. Estudios sobre el barroco. Bucaramanga: UIS, 1965. Impreso.

Hauser, Arnold. Historia social de la literatura y el arte. Madrid: Guadarrama, 1951.Impreso.

Mainer, José Carlos. Historia mínima de la literatura española. Madrid: Turner, 2014.Impreso.

Oliva, César. "La dama boba, hoy". El escritor y la escena, V. Estudios sobre el teatro español y novohispano de los Siglos de Oro. Homenaje a Marc Vitse. 1997. 39-48.Impreso.

Pérez-Sierra, Rafael. "Versión cinematográfica de El perro del hortelano". Lope de Vega: comedia urbana y comedia palatina. Actas de las XVIII Jornadas de Teatro Clásico. Almagro, 11, 12 y 13 de julio de 1995. 1995.107-114.Impreso.

Romanos, Melchora. Algunas cuestiones acerca de las relaciones entre polimetría y dramaturgia en el teatro de Lope de Vega. Actas del VII Congreso de la AISO. Vol. 539, 2006.Impreso.

Trecca, Simone. La adaptación fílmica de La dama boba. VIII Congreso de la Asociación Internacional Siglo de Oro. 3 vols. 2011.467-475.Impreso.

Vega Carpio, Lope de. "El arte nuevo de hacer comedias en este tiempo."

Ed. Juana de José Prades. Madrid: Consejo Superior de Investigaciones Científicas, 1971.Impreso.

Vega Carpio, Lope de. "La dama Boba. La moza de Cántaro.” Introducción de Rosa Navarro Durán. Barcelona: Planeta, 1994.Impreso.

Vega Carpio, Lope de. El perro del hortelano. Madrid: Castalia, 2000.Impreso. 